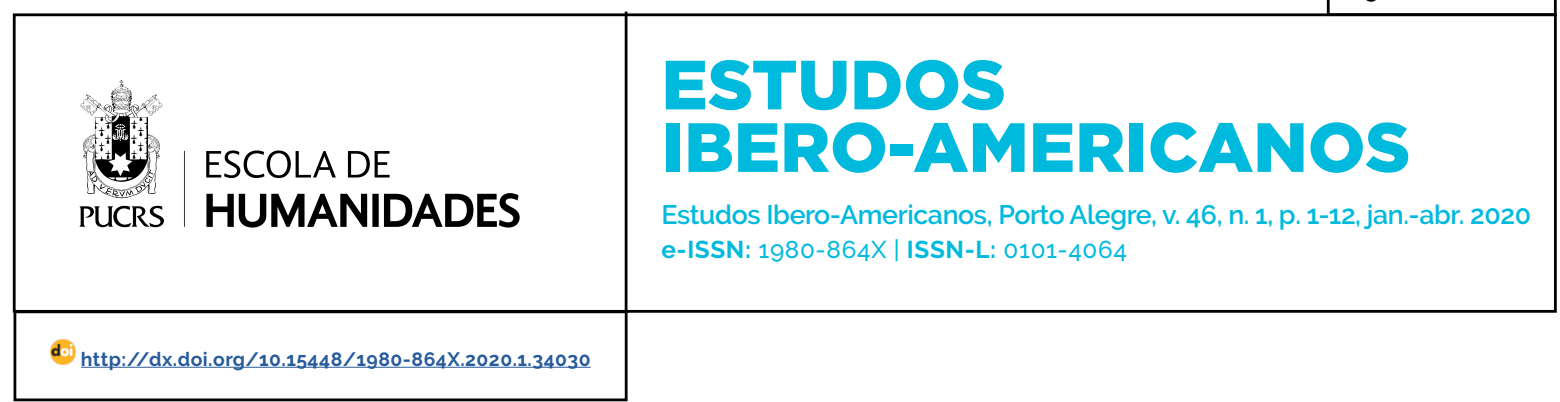

DOSSIÊ

\title{
José Mármol e o ambiente brasileiro do século XIX visto por um exilado
}

\author{
José Mármol y el ambiente brasileño del siglo XIX visto por un exilado \\ José Mármol and the brazilian environment of the $19^{\text {th }}$ century as seen by an exile
}

\section{Amanda da Silva \\ Oliveira $^{1}$ \\ orcid.org/0000-0003-3793-1450 \\ amanda.oliveira@ufsm.br}

\section{Maria Eunice Moreira ${ }^{2}$ \\ orcid.org/0000-0003-1019-8519 \\ maria.eunice@pucrs.br}

Recebido em: 5 jul. 2019.

Aprovado em: 24 jul. 2019.

Publicado em: 22 abr. 2020.
Resumo: O ambiente da América Latina é a oportunidade de negação das engenharias de um velho mundo, com uma arquitetura pensada na maneira como as novas luzes, de pensamento social e de constituição identitária podem ser atuantes no espaço de construção e de formação de uma nova nação. A concepção de ciudad signo representa a constância de uma nova ordem de entendimento de mundo, em que as cidades latino-americanas, a população e os intelectuais se fundaram e se desenvolveram ao mesmo tempo. Dessa forma, o presente artigo apresenta a relação entre a noção de história ambiental e de projeto identitário, na América Latina, região geográfica que se estabeleceu por meio da ideológica busca pela sua própria caracteristica de identificação. A estrutura do trabalho conta com uma breve introdução, para situar o recorte temático do estudo, e três pontos de abordagem: no primeiro, uma breve discussão sobre o termo "história ambiental", baseado no pensamento crítico de Enrique Leff, e como esse termo se estrutura na construção da América Latina; no segundo, o caso de José Mármol, argentino exilado no Brasil que, pensador da época, escreve em periódico brasileiro e aborda temáticas sobre o entendimento do ambiente local e como esse interfere na formação social dos nativos; e no terceiro, a análise dos oito escritos do literato argentino, publicados no periódico Ostensor Brasileiro. Como conclusão, desenvolve-se uma breve reflexão do papel que a literatura latino-americana desempenha no processo de ambientalização dos espaços físicos, e como se torna instrumento efetivo de interpretação e de constituição da história ambiental, proposta por Leff.

Palavras-chave: História ambiental. Identidade. Século XIX. Literatura latino-americana.

Abstract: Latin America is a place based on the denial of Old-World architecture. Its conception offers the possibility of constructing a physical reality, different from that prevailing in the European continent, given its varied geographical and spatial perspective. According to Angel Rama, the city thus becomes the sign representing the new order and opens as the space that can embrace all the dreams of this new spatial understanding, since it is configured to be modern and ideologically opposed to its place of origin. This article presents the relation between the notion of environmental history and the identity project in Latin America, a geographical region that was established through the ideological search for its own characteristics. The constitutional reality of Latin America was through its physical space, an American dream, as said by Ángel Rama. In order to do so the text is composed by a brief introduction, stating the thematic perspective of the study, and three approaches: the first presents a discussion about the term "environmental history", based on the critical thinking of Enrique Leff, and how this term is structured in the construction of Latin America; the second focuses on the case of José Mármol, an Argentinean exiled in Brazil in the first half of the 19th century, who wrote articles on the local environment for the Ostensor Brasileiro, a Rio de Janeiro newspaper, and how it interfered with the social identity formation of the natives; the third brings the eight texts of the Argentinean writer, published in the newspaper. As conclusion, a short reflection on the role that Latin American literature plays in the process of environmentalization of physical spaces, and how it becomes an effective instrument of interpretation and constitution of environmental history, as proposed by Enrique Leff.

Keywords: Environmental history. Identity. 19th century. Latin American literature.
Artigo está licenciado sob forma de uma licença Creative Commons Atribuição 4.0 Internacional. 
Resumen: El ambiente de América Latina es la oportunidad de negación de las ingenierias de un viejo mundo, con una arquitectura pensada en la manera como las nuevas luces, de pensamiento social y de constitución identitaria pueden ser actuantes en el espacio de construcción y de formación de una nueva nación. La concepción de ciudad signo representa la constancia de una nueva orden de entendimiento de mundo, en que las ciudades latinoamericanas, la población y los intelectuales se fundaron y se desarrollaron al mismo tiempo. De esa forma, el presente articulo presenta la relación entre la noción de historia ambiental y proyecto identitario, en América Latina, región geográfica que se estableció por medio de la ideológica búsqueda por la su propia característica de identificación. La estructura del trabajo cuenta con una breve introducción, para situar el recorte temático del estudio, y tres puntos de abordaje: en el primero, una breve discusión sobre el término "historia ambiental", basado en el pensamiento crítico de Enrique Leff, y como ese término se estructura en la construcción de América Latina; en el segundo, el caso de José Mármol, argentino exilado en Brasil que, pensador de la época, escribe en periódico brasileño y aborda temáticas sobre el entendimiento del ambiente local y como este interfiere en la formación social de los nativos; en el tercero, el análisis de los ocho escritos del literato argentino, publicados en el periódico Ostensor Brasileiro. Como conclusión, se desarrolla una breve reflexión del papel que la literatura latinoamericana desempeña en el proceso de ambientalización de los espacios físicos, y como se torna instrumento efectivo de interpretación y de constitución de la historia ambiental, propuesta por Leff.

Palabras clave: Historia ambiental. Identidad. Siglo XIX. Literatura latinoamericana.

"Não escrevemos para que nos acreditem, mas sim para que nos ouçam". (José Mármol)

"Me pone miedo el sol de acá". (José Mármol)

\section{Introdução}

A América Latina constitui-se como um espaço para a negação da arquitetura do Velho Mundo. Sua concepção traduz a possibilidade de construção de uma realidade física, diferente daquela vigente no continente europeu, porquanto outra será a sua perspectiva geográfica e espacial. Segundo Ángel Rama, a cidade tornase, assim, o signo representativo da nova ordem e abre-se como o espaço que pode abarcar todos os sonhos dessa nova compreensão espacial, pois se configura para ser moderno e ideologicamente oposto à sua matriz. Dessa forma, a cidade latino-americana é composta por meio de um "parto de la inteligencia", "el sueño de un orden", (RAMA, 1998, p. 17) nas palavras de Rama, pois conforma-se diferentemente da organização da cidade medieval europeia. Nasce, com a cidade latino-americana, uma nova época do mundo: a "América fue la primera realización material de ese sueño y, su puesto, central en la edificación de la era capitalista" (RAMA, 1998, p. 18).

A concepção de ciudad signo representa a constância de uma nova ordem de entendimento de mundo. As cidades latino-americanas, a população e os intelectuais se fundaram e se desenvolveram ao mesmo tempo, e o signo passou "a significar dentro del interior del conocimiento" (RAMA, 1998, p. 19). A organização circular das cidades, por exemplo, "situaba el poder en el punto central y distribuía a su alrededor, en sucesivos círculos concéntricos, los diversos estratos sociales" (RAMA, 1998, p. 20). Estabelecer o poder no centro é evidenciá-lo como também central na constituição geográfica, não só hierárquica, mas fisicamente significativa.

A palavra escrita, nesse sentido, toma importância fundamental e passa a ser registro de mundo, de relato, de fatos, e também de memórias, constituições identitárias, de busca pela autonomia social. A importância da palavra escrita, contrapondo-se à palavra falada, que representava a precariedade e a primitividade, é posta a esse serviço: "la escritura poseia rigidez y permanência, un modo autónomo que remedaba la eternidad" (RAMA, 1998, p. 22).

O presente artigo analisa a relação entre a noção de história ambiental e de projeto identitário, na América Latina, região geográfica que se estabeleceu por meio da ideológica busca pela sua própria característica de identificação. A realidade constitucional da América Latina deu-se por meio de seu espaço físico, um sonho americano, nas palavras de Ángel Rama.

Para desenvolvimento da proposta, o texto conta com uma breve introdução, para situar o recorte temático do estudo, e três pontos de abordagem: o primeiro apresenta uma breve 
discussão sobre o termo "história ambiental", baseado no pensamento crítico de Enrique Leff, e como esse termo estrutura-se na construção da América Latina; o segundo enfoca o caso de José Mármol, argentino exilado no Brasil, na primeira metade do século XIX, e que escreve, no Ostensor Brasileiro, periódico do Rio de Janeiro, artigos sobre o ambiente local e como esse interfere na formação identitária social dos nativos; e o terceiro recai sobre os oito textos do literato argentino, publicados no referido periódico. À guisa de conclusão, desenvolve-se uma breve reflexão do papel que a literatura latino-americana desempenha no processo de ambientalização dos espaços físicos, como instrumento de interpretação e de constituição da história ambiental, proposta por Leff.

\section{Da construção da América Latina por meio de sua história ambiental}

As questões relativas ao ambiente colaboram para a compreensão da realidade social latinoamericana. Ángel Rama entende a constituição do território americano por meio de uma sociedade letrada, mas destaca a estrutura da cidade como ambientação que intercala os desejos da nova terra e a ideologia do novo mundo na organização geográfica do espaço físico da América Latina.

A construção de uma história ambiental é sinalizada, também, por Enrique Leff. Segundo discorre no artigo "Construindo a história ambiental da América Latina", o ambiente é um elemento que "irrompeu no discurso político e cientifico de nosso tempo como um conceito que vem ressignificar as concepções de mundo, de desenvolvimento, da relação da sociedade com a natureza, de tempo e da sustentabilidade da vida" (LEFF, 2007, p. 11). Mais do que isso,

o ambiente emerge como um pensamento holístico que busca reintegrar as partes de uma realidade complexa: é o campo de saber que viria completar as visões parciais e o desconhecimento da natureza por parte dos paradigmas científicos da modernidade. (LEFF, 2007. p. 11, grifo do autor).

A "ambientalização" de disciplinas científicas, de práticas profissionais e de ações sociais é o que Leff destaca como novas perspectivas de entendimento do termo como uma "nova indagação sobre o tempo, sobre as temporalidades que definem os processos ecológicos e as identidades culturais que se integram com os processos econômicos e tecnológicos que marcam o curso da história moderna" (LEFF, 2007, p. 12). É no processo de formação de um contexto intelectual que ocorrerá "o encontro de racionalidades diferenciadas para cuja abordagem a definição genérica de ambiente como o campo das relações sociedade-natureza abre a porta dos estudos de suas complexas interações" (LEFF, 2007, p. 12). Nessa perspectiva, a história ambiental entende a complexidade ambiental como um processo que está intrincado entre as relações racionais e culturais dos indivíduos, em que problematiza relações como ecologia e economia por meio dos campos de poder e de cultura, em um tempo não tão "natural", mas sim, e sobretudo, "humano", na construção do que o autor chama de "história do ser" (LEFF, 2007, p. 14, grifo do autor). De forma concisa, Leff (2007, p. 15) esclarece:

O saber ambiental é um olhar holistico,
um pensamento da complexidade que
emerge da desconstrução do logocen-
trismo e o descentramento do circulo das
ciências. Esse saber encontra seu referen-
te na construção social da complexidade
ambiental: a complexificação do real, do
conhecimento, da produção, da racio-
nalidade, do tempo e das identidades.

Ao entender o saber cultural como uma transcendência da cultura, Leff chama a atenção para a construção desse conceito, que se forma da união entre a materialidade e o simbólico. Essa aproximação tem a ver com a questão entre passado e futuro, na qual a inter-relação mobiliza relações interdisciplinares, num diálogo de saberes, pois "reflete um processo em que o real se entrelaça com o simbólico em diferentes visões, racionalidades e perspectivas históricas mobilizadas por interesses sociais diversos" (LEFF, 2007, p. 16).

Ampliando essa ideia, é possivel propor a "reconfiguração das identidades que renascem do silêncio da história - de seres culturais subjugado 
e dominados -, como uma resiliência cultural que hoje reafirma sua etnicidade e suas tradições ancestrais, em uma vontade de ser" (LEFF, 2007. p. 17. grifo do autor). Para Leff, "as identidades - que são a expressão da permanência do humano inscrito no ser e no tempo, no corpo e no meio -, se re-configuram em relação com as transformações do seu contexto econômico e político" (LEFF, 2007, p. 17), possibilitando a atualização das origens ao mesmo tempo em que "se reconstitui em um processo de afirmação da diversidade e da diferença" (LEFF, 2007, p. 17).

Para entendimento do que Leff chama de "Hermenêutica das visões de natureza e recuperação de relatos de destruição ecológica", podem ser incluidos

a exegese de conteúdos e sentidos 'ambientais' de textos e documentos históricos; as interpretações possiveis de autores 'ambientais' e precursores do ambientalismo; a análise dos diversos 'conceitos de natureza', em discursos teóricos e literários, sobre as relações ecológico-culturais. A história ambiental abre uma via para o estudo das narrativas dos diferentes atores sociais ao longo da história, sobre suas visões das relações de dominação que sucedeu sobre diferentes formações sociais e seu entorno. Esta revisão histórica não somente permitirá desentranhar os diferentes conceitos de natureza de diferentes culturas, mas também trazer a luz os silêncios de suas histórias ocultas (LEFF, 2007, p. 17-18).

Como destaca o autor, "a história continua a ser narrada pelos vencedores" (LEFF, 2007, p. 18). Contraposta a essa perspectiva, a história ambiental coloca-se como uma narrativa dos vencidos, que justamente por meio dos saberes subjugados, agora podem se expressar, formando a história de histórias não ditas:

e não somente porque a natureza não fala e porque os pobres, os colonizados, os dominados e os vencidos foram silenciados, e sim porque a subjugação da natureza foi um processo silencioso, invisivel e impensado pelos paradigmas civilizatórios que justificavam a exploração da natureza em nome do progresso e do poder (LEFF, 2007, p. 18).

Ao entender a história como a possibilidade de construção e de reconstrução do passado, é possivel desenterrar histórias esquecidas, agregando valor no que não era permitido chegar à luz da história oficial. Recontar e/ou rever, editar, atualizar são ações que, impossibilitadas em nome de uma memória de vencedores, atualmente parecem compactuar com a necessidade de que as memórias coletivas e plurais, cada vez mais, tenham espaço, não como forma de quebrar tradições e identidades, mas sim, fundamentalmente, para ressignificá-las, "abrindo novos caminhos no fluxo da história" (LEFF, 2007, p. 19). Essa concepção poderá atuar para a "emancipação dos sentidos reprimidos por uma história de conquista, de subjugação e holocausto" (LEFF, 2007, p. 19). Nessa direção, coloca-se a possibilidade de ressignificação de identidades marcadas por diferentes processos históricos, e que se reorganizaram a partir dessas matrizes:

É a reabertura dos sentidos da história e a existência, a partir da qual se encontram os tempos da história e se decantam em identidades hibridas, em que se enlaçam a história natural, a tecnologia e a ordem simbólica; espaço em que se articulam as ciências transformadas por um saber ambiental; crisol onde se fundem os tempos passados, unitários e mensuráveis, e de onde irradia um futuro projetado para a diferença, mobilizado pela outridade e seduzido pelo infinito. Esta transcendência não é um projeto e nem um desenvolvimento da realidade existente, e sim a criação de algo novo a partir da reemergência de identidades que conservaram as marcas de suas diversas histórias, para enraizar-se em um território em que se sustentam novos sentidos civilizatórios (LEFF, 2007, p. 21).

A consciência ambiental não só reconhece e recupera o passado, "passado de esquecimentos e subjugação, como o dos povos dizimados e subjugados, ao mesmo tempo em que se processa a destruição da natureza" (LEFF, 2007, p. 23), mas promove o questionamento desse passado silenciado, recuperando-o e tornando-o, com a sua especificidade, a dimensão pluridimensional das visões e os pontos de vista do que configura as narrativas sociais como marcas sintomáticas de uma memória coletiva 
mais abrangente e menos excludente.

Nessa perspectiva, não se trata, como sinalizado pelo autor, de "uma simples hermenêutica, uma reintegração da história contra a versão dos vencedores" (LEFF, 2007, p. 23), mas de uma abertura das "diversas vias de investigação, que traçam diferentes caminhos metodológicos de reconstrução" (LEFF, 2007, p. 23). Assim, para uma construção social da história ambiental da América Latina, Leff acredita que, dentre outras perspectivas, a recuperação de textos e de documentos de estudiosos constituem uma via importante e que pode aportar novos entendimentos a essa história. Esses materiais são indícios e sinalizam o que ele acredita ser formas de construção de um futuro social mais sustentável:

Isto implica em [sic] superar a constituição de uma história ambiental como paradigma interdisciplinar para dar seu lugar a um saber ambiental, integrado pelos saberes dos atores históricos que estão construindo, dentro das estratégias de poder postas em jogo pelo discurso e pelas políticas do desenvolvimento sustentável, o projeto cidadão de construir sociedades sustentáveis (LEFF, 2007, p. 26).

No Brasil, o trânsito de periódicos e o investimento na cultura letrada oportunizaram aos escritores deixar registradas as suas impressões de sociedade por meio da imprensa. Nesse caso, incluem-se os literatos, que, incentivados pelo império cultural de Pedro II, construiram um imaginário ambiental do Brasil no século XIX, compartilhando impressões e identificações com a cena natural local do Rio de Janeiro, mas e sobretudo, visões do espaço físico e de como o ambiente interagia e reagia ao complexo ideológico de uma identidade americana.

\section{Dos literatos argentinos e José Mármol}

Em estudo anterior sobre os "Literatos argentinos e brasileiros no império de Pedro II: algumas anotações", foi destacado como o espirito de época do Brasil, sob o comando de Pedro II, foi fundamental para a constituição identitária das letras em nosso País. O Imperador brasileiro não só estimulou a cultura brasileira, como concretamente criou mecanismos para a sua construção. Bastam citar duas instituições por ele instituidas para aquilatar a importância de sua visão: em 1838, foi fundado sob os seus auspícios o Instituto Histórico e Geográfico Brasileiro e, em 1839, foi criada a revista do Instituto, para publicações de estudose pesquisas, financiados por recursos imperiais, para possibilitar a divulgação do vasto e heterogêneo País que governava.

A abertura que a cultura e as letras apresentaram no governo de Pedro II revelava a imagem de um governante favorável às artes e às ciências. Isso oportunizou a vinda de artistas e pesquisadores, da Europa e da América Latina, para o território brasileiro. Na abertura do País aos estudiosos e literatos, muitos exilados aqui encontraram um ambiente profícuo para escritas e ideias, contexto contrário aos de seus próprios países, em função de questões políticas. Dessa realidade, constata-se que os argentinos, ao fugir do governo ditatorial de Juan Manuel Rosas², escolheram o Brasil por ser uma nação na qual puderam se estabelecer, escrever e desenvolver pesquisas e posicionamentos críticos, o que alterou e ampliou os registros documentais do Brasil daquela época.

José Mármol ${ }^{3}$ é um desses jovens argentinos que, contrário à política de Rosas, deixa a Argentina, e fixa-se no Rio de Janeiro em 1843. onde permanece por três anos. Logo, estabelece relações com os escritores românticos brasileiros e, consequentemente, com o movimento nacionalista que movimentou essa geração. Além do contato com os intelectuais que contribuiam para os periódicos da época, o argentino atuou

\footnotetext{
2 "Juan Manuel Rosas fortalece-se como governador, centralizando o poder nacional. A decorrência desse estado político é o exilio dos jovens que participaram do Salão Literário de 1837 que, para fugir de Rosas, viajam ao Brasil. O estado político do Brasil e da Argentina é, pois, distinto: entre os argentinos, a ditadura de Rosas afasta os intelectuais; no Brasil, a monarquia de Pedro abre espaço para a manifestação de homens da cultura e da literatura, e o pais começa a vivenciar um nucleamento no campo da cultura, em especial, da literatura, a partir da criação do Instituto Histórico e Geográfico Brasileiro" (MOREIRA,2015, p. 231).

3 O argentino José Mármol exila-se no Brasil, apesar de seu caminho inicialmente ser o Chile, fugindo da ditadura de Juan Manuel de Rosas, que ocorre na Argentina no periodo entre 1829-1832 e 1835-1852.
} 
de maneira ativa e expôs seus pensamentos nas páginas da imprensa local.

A contribuição mais significativa de José Mármol encontra-se no periódico Ostensor Brasileiro, onde publicou textos críticos nos anos de 18451846. Fundado por Vicente Pereira de Carvalho Guimarães e João José Moreira, o Ostensor Brasileiro representava à época certa resistência ao projeto imperial nacionalista e destacou-se como uma das primeiras e mais importantes publicações literárias da imprensa brasileira. $\mathrm{Na}$ folha de rosto constava a descrição de que correspondia a uma "Collecção de producções originaes em prosa e verso sobre assumptos pertencentes á historia politica e geographica da Terra de Santa Cruz"4.

É nesse jornal que Mármol encontra espaço para a publicação de seus ensaios, organizados em duas séries: "Fragmento da minha carteira de viagem" e "Juventude Progressista do Rio de Janeiro".

\section{Dos textos de José Mármol em Ostensor Brasileiro}

Em "Fragmento da minha carteira de viagem", Mármol apresenta a sua opinião sobre a visão estrangeira do território; a natureza feminina pelo olhar masculino; e a sociedade atual pela visão nostálgica do passado. Basicamente divididos em três temas - a natureza, a natureza do homem e a natureza social -, Mármol expõe o seu pensamento por meio de um discurso que alia a nostalgia de um tempo puro e recatado, de natureza abundante e próspera, a uma realidade hipócrita, pecaminosa e perdida, feita pelos homens - e pelas mulheres, que se destacam como o elemento profano do ambiente paradisíaco daquele Brasil.

No primeiro texto de "Fragmento da minha carteira de viagem", Mármol inicialmente já se posiciona como o olhar estrangeiro, e, "mais à mercê do instinto, que da própria vontade"5 (MÁRMOL, 2010, p. 229), observa o ambiente local. As sensações climáticas da capital imperial contribuem para a bela recepção que o espaço confere ao observador: "e o Rio de Janeiro, este país privilegiado pela mão de Deus, com a cópia dos panoramas do teu Paraíso encantado, é a gruta fantástica do jardim tropical" (MÁRMOL, 2010, p. 229).

A relação entre a natureza e a espacialidade da cidade une-se à ideia de religiosidade, em que "uma admiração religiosa se apodera da alma, ante a sua esplêndida natureza, que como uma idealização da divindade, se banha nas ondas de ouro do sol brasílico" (MÁRMOL, 2010, p. 229). A sensação de bem-estar que desfruta na terra estrangeira confere-lhe paz e serenidade, pois não a entende como do outro, mas sim um outro espaço que também o pertence: "cruzei os braços sobre o peito, e contemplava, quase com um sentimento de orgulho, este belo pedaço da minha adorada América" (MÁRMOL, 2010, p. 229).

A sensação de pertencimento ao novo território permite ao estrangeiro exercer os seus questionamentos sobre essa realidade, questionamentos esses que serão constantemente reiterados ao longo de seus escritos: "Por que razão o Gênio se não eleva na América à altura de sua natureza, e dos destinos que deve representar no mundo, quando a mão dos séculos tiver roçado um pouco mais a crista dos Andes?" (MÁRMOL, 2010, p. 229). Esse "problema moral" direciona-o a abordar essas inconsistências por meio da natureza de "seus filhos" ou de "sua época". Nessa oposição, ele acredita que a primeira não é possivel, pois "a natureza moral do homem nunca é menos forte e bela, que a natureza física que o rodeia" (MÁRMOL, 2010, p. 229). Talvez seja a segunda, a inconsistência de uma época, a sua preocupação inicial, sendo o objetivo dos ensaios a tentativa de representação desse registro histórico de um tempo, mas sem o compromisso de assim o afirmar, pois "apenas apontaremos as ideias que nos inclinam a acreditá-lo" (MÁRMOL, 2010, p. 229).

A experiência da escravidão, para o autor, sinaliza as crenças em que o povo está inserido. Se "durante a vida de sua escravidão, adquiriram uma crença, - a crença religiosa" (MÁRMOL, 2010, p. 229, grifo do autor), também após, "durante a

\footnotetext{
Disponivel em: https://bndigital.bn.gov.br/artigos/ostensor-brasileiro-jornal-litterario-e-pictoreal/. Acesso em: 15 fev. 2019 Os textos de José Mármol, publicados no Ostensor Brasileiro, foram atualizados conforme a ortografia vigente.
} 
vida da liberdade, adquiriram outra crença. - a de sua independência politica" (MÁRMOL, 2010, p. 229, grifo do autor). Essas crenças, porém, não foram suficientes para a efetiva independência do Gênio americano, pois "a mesma causa que produz a escravidão da consciência americana, às crenças europeias, em filosofia, legislação, ciências, artes, literatura, e ainda nos costumes, é a que produz o abandono do Gênio americano, para seu engrandecimento e originalidade" (MÁRMOL, 2010, p. 229). Dessa forma, a América só encontrará a sua liberdade quando a civilização "se derramar sobre as frontes de teus filhos" (MÁRMOL, 2010, p. 229). Para isso, por meio da independência politica dada pelos nossos pais, "somos nós, seus filhos, os que devemos dar conta às gerações futuras do emprego que fizemos de nossa época" (MÁRMOL, 2010, p. 229), continuando a luta em nome da revolução pela independência intelectual. A literatura, nesse aspecto, corresponde a um projeto de autonomia, porque somente "depois de ter conseguido tudo isto, teremos uma literatura e um Gênio americanos" (MÁRMOL, 2010, p. 229).

No segundo texto de "Fragmento da minha carteira de viagem", intitulado "A poesia e o matrimônio", compara as duas temáticas, apontando semelhanças e diferenças. Entende a poesia como a "palavra adaptável a todas as definições, como a virtude" (MÁRMOL, 2010, p. 248), e liberta de sentidos únicos, pois "que cada um tem direito de entendê-lo a seu modo, como a liberdade de imprensa, e que eu me absterei de definir" (MÁRMOL, 2010, p. 229). Por outro lado, não se abstém de definir o matrimônio, "outra coisa igualmente eterna, porque é mais da desgraça humana" (MÁRMOL, 2010, p. 250), coisa essa que "é o instinto que aproxima o homem à mulher" (MÁRMOL, 2010, p. 250), um instinto complexamente caracterizado como "semidivino, semi-infernal" (MÁRMOL, 2010, p. 250). Para Mármol, o matrimônio particulariza-se como a "união indissolúvel de um só homem com uma só mulher; salvo as exceções que traz consigo toda a regra geral, por muito boa e santa que ela seja" (MÁRMOL, 2010, p. 250, grifo do autor).
Seu pensamento revela um posicionamento moral-religioso latente: "falamos do matrimônio católico, o melhor que conhecemos, porque somos católicos, e não podemos dizer outra coisa" (MÁRMOL, 2010, p. 250).

A relação entre poesia e matrimônio colocase de maneira antagônica, pois, nas palavras do autor, "há também duas coisas heterogêneas na ordem moral, como a água e o fogo na ordem física, como a assembleia representativa e o ministério responsável na ordem social, e como a pobreza e a felicidade na ordem doméstica. Estas duas coisas são a poesia e o matrimônio" (MÁRMOL, 2010, p. 250), como se um tema excluisse o outro: "o poeta cômico faz descer o pano com o casamento que termina a sua comédia; primeiro, porque a bênção nupcial é o ofício de defuntos da poesia; segundo, porque todos sabem o que o poeta cala" (MÁRMOL, 2010, p. 250). Em outras palavras, a arte liberta, enquanto o casamento trancafia: "não há comédia que principie por um casamento, e há muitas que começam por um enterro; o que prova que um enterro é menos prosaico que um matrimônio" (MÁRMOL, 2010, p. 250).

O elemento que une a poesia e o matrimônio é o sujeito feminino: "toda a poesia da vida se acha personificada nesse céu inconstante que se chama mulher: nesse belo defeito da natureza" (MÁRMOL, 2010, p. 250, grifo do autor). A mulher, assim como a poesia, é bela quando liberta - e solteira; quando casada, aprisiona-se e como que perde o encanto ao poeta: "e sua alma! oh! A alma de uma mulher solteira e virgem é a metade de sua poesia, como um marido zeloso a metade de sua desgraça" (MÁRMOL, 2010, p. 250). A beleza da mulher desnaturaliza-se por meio do casamento, "mas, casa-se esta mulher, e começa a prosa, bem como a prole: adeus braços, adeus olhos, adeus tudo; sai a poesia pela mesma porta, por onde entrou o marido!" (MÁRMOL, 2010, p. 250). E tudo isso por apenas uma justificativa: "desde que nada temos a desejar na mulher, nada temos a admirar. Desde que nada admiramos, nada poetizamos" (MÁRMOL, 2010, p. 250).

Em suma, constata: "mas quando dizemos que 
a poesia e o matrimônio não andam jamais unidos, livre-nos Deus de querer dizer com isso que aquela é o patrimônio de todas as mulheres solteiras. Isto também tem suas exceções, como a constância de todas elas" (MÁRMOL, 2010, p. 250). E finaliza:

se a poesia é filha do céu, como disse Homero, o matrimônio não é seu irmão; sem querer por isto que seja filho do inferno, como parece pretendê-lo George Sand. Será filho de algum outro; conhecemos grande número de bons filhos de maus pais (MÁRMOL, 2010, p. 251).

No terceiro e último texto de "Fragmento", novamente tematiza a natureza feminina, agora sob a perspectiva de uma moral de costumes sociais. Se, no texto anterior, a mulher podia desabrochar na poesia, mas a vida de casada a tornava não mais interessante aos dotes artísticos do poeta, esse artigo já evidenciaria a mulher como corrompida pela natureza dos homens, pelos costumes urbanos, pela superficialidade da cultura provinciana da América.

Inicialmente, ao tratar da verdade, e de que "não sei se a verdade é coisa existente em a natureza, ou se é uma dessas abstrações relativas que existem no cérebro dos homens" (MÁRMOL, 2010, p. 257), entende que "na ordem moral, a verdade é talvez mais problemática" (MÁRMOL, 2010, p. 257). Talvez, justamente, pela natureza do homem: "isto procede de não estar a verdade na analogia que existe entre os fenômenos físicos ou morais e a nossa consciência, e sim nos mesmos fenômenos, aos quais a razão julga compreender, porque tem vontade disso. Seja qual for a verdade, é neles encontrada, porém nunca em nossos juizos, que só têm a garantia que lhes quer dar a nossa vaidade" (MÁRMOL, 2010, p. 258).

A verdade, nas palavras de Mármol, é a relação entre a aparência e a crença: "na sociedade, basta que uma coisa exista em aparência, e que algumas dúzias de pessoas acreditem nela, para que seja classificada como verdadeira" (MÁRMOL, 2010, p. 251). A natureza feminina, nesse aspecto, está corrompida,

direi pois que ficamos sem mulheres, porque se estão transformando em homens em nossas mãos. Nem mais nem menos; e no andar que levam. antes de meio século ficará o mundo sem mulheres. Houve uma época, feliz a certos respeitos para o gênero humano, em a qual a mulher era o íris formoso dos homens (MÁRMOL, 2010, p. 251).

Ao rememorar os tempos de cavalheirismo e galanteria, Mármol faz uma avaliação negativa das mulheres do século XIX, como se o valor da sociedade de sua época não fosse o mesmo que dos tempos anteriores. Para ele, "elas nos fogem - e já não têm de mulher senão a figura e a metade do vestido; - dentro em pouco lhes ficará somente a figura" (MÁRMOL, 2010, p. 251). As mesclas de papéis sociais masculinos e femininos estão em todos os lados, "a politica, a literatura, e a honra alheia sobre tudo, são as conversações da moda" (MÁRMOL, 2010, p. 251), e não lhe é concebivel que mulheres estejam nos mesmos círculos sociais, agindo como homens: "Deus nos livre de nos acharmos em noite de conversação geral em qualquer sala. Sobretudo se há desses cavaleiros instruídos de 18 anos que resolvem problemas literários com mulheres de 15!" (MÁRMOL, 2010, p. 251).

O tom derrotista do final do ensaio é categórico: "e o pior é que não há remédio para semelhante mal" (MÁRMOL, 2010, p. 251). A América, dessa maneira, é punida; talvez esse seja o grande erro para a conquista de uma efetiva liberdade do povo, em nome do Gênio americano. Mármol sentencia:

Pobre América minha! Tu conservavas em teus velhos costumes o que devia ser para sempre velho; isto é, querias que tuas mulheres fossem mulheres: porém, quão longe estavas de pensar que, ao fazer com a Europa os teus tratados de amizade e comércio, a tua boa amiga te introduziria por contrabando, entre os caixões de suas mercadorias, o grande-tom de sua moderna sociedade. Esse grande-tom, que, à força de engrandecer-nos, faz rebentar a muitos de nós! (MÁRMOL, 2010, p. 251).

A cidade do Rio de Janeiro e seus costumes é vista por Mármol, através de suas notas pessoais, na mesma perspectiva com que estabelece a relação entre natureza e cultura. Não the parece comum os costumes de uma sociedade 
fortemente influenciada pela Europa, e que essa influência extrema - sobretudo com Paris - deve ser nociva a um projeto de América, de identidade local, de reconhecimento identitário, de independência efetiva do "Gênio americano". De alguma forma, os textos de "Fragmento da minha carteira de viagem" descortinam as impressões etnográficas do autor que, ora mais, ora menos, coloca-se como sujeito atuante e participativo das vitórias e das derrotas da autonomia da identidade americana. Por outro lado, são reveladores do olhar de um exilado sobre a cena carioca mas, de modo efetivo, sugerem que as relações entre a natureza e a cultura estão imbricadas para a realização do "projeto América". A cultura é facilmente levada em conta por interesses e por frivolidades, enquanto o ambiente interfere na visão dessa forma de ver, mas é negligenciado em nome dos interesses e costumes da moda. Como um sociólogo, Mármol mapeia os costumes dos brasileiros residentes do Rio de Janeiro do século $X I X$, fazendo juizos de valor que questionam justamente esse modus vivendi em nome de uma ideia de ambiente que se coloca necessária para a politização do território. Enfim, a natureza é subjugada em prol dos interesses mundanos.

Além de ensaiar sobre a vida cotidiana dos cariocas, José Mármol inaugura, nos textos escritos sob o título de "Fragmento", a maneira como conduzirá o seu outro conjunto de ensaios, intitulado "Juventude Progressista do Rio de Janeiro". Os ensaios, identificados apenas pelo número de ordem (I, II, III, IV e V), apresentam a posição do jovem na construção identitária do País. O texto I aborda, em linhas gerais, a juventude carioca e sua arma de luta - a imprensa e o periódico; o texto II centra-se na ausência de identidade própria da cidade do Rio de Janeiro, em variados setores, como a política e a literatura, destacando o caráter europeu de suas influências; o texto III apresenta o argumento de que é a literatura a arma identitária da juventude progressista; o texto IV tem como tema a América e a Europa, e as relações de herança de uma para/ com a outra; e o texto $\vee$ apresenta a percepção do autor quanto à formação cultural europeia em território americano: um bom exemplo para se inspirar, para a que a efetiva independência ocorra, para, depois, romper com essa influência.

Inicialmente, Mármol define que

o progresso não é, como alguém crê. um atributo inerente a todo o homem jovem: em uma geração nova encontra-se uma nímia fração que progride, que segue as leis da natureza e do tempo; e outra fração considerável que não faz senão nascer, vegetar e morrer. Progredir é desenvolver-se com o sucesso e com o tempo, seguir o curso da revolução contínua em que se agita a natureza moral, e não estacionar-se (sic) em ideia alguma, em princípio algum, que não sejam a expressão das necessidades do momento. A mocidade que concebe e põe em prática esta verdade com seus meios inteligentes é a que se chama Juventude Progressista (MÁRMOL, 2007, p. 408, grifo do autor).

Para ele, a Juventude Progressista consiste naqueles que reconhecem o atraso do seu território político: "reconhece-se em todas as sociedades civilizadas por uma espécie de poder despótico que exerce voluntariamente sobre o resto da sociedade a quem domina" (MÁRMOL, 2010, p. 409). Além disso, é essa juventude a que deve comandar o povo para a abertura do movimento, pois

o povo a ouve: o povo respeita-a: o povo
revolta-se em seu favor, levanta-a, e
defende-a: porque o bom senso, única
ilustração, único talento do povo, chega
a compreender cedo que as ideias da
juventude são as suas, porque toda a
mocidade é revolucionária por essência,
e todo o povo é uma revolução que fala,
que se move, e se transmite (MÂRML,
2010, p. 409).

E essa juventude atua nos veículos de comunicação: "na Europa, como na América, a encontrareis ativa, compacta, dominante, achála-eis senhora da imprensa periódica" (MÁRMOL, 2010, p. 409).

A escrita é, portanto, a arma da Juventude Progressista, e o periódico, o veículo pelo qual podem circular as ideias libertárias: 
o periódico é na época em que vivemos a alavanca moral que levanta e conduz ao progresso a sociedade cristã, - é o exército que defende e triunfa, - o tesouro poderoso, - a política previdente, - a religião em sua essência, - a civilização em sua análise e sua sintese (MÁRMOL, 2010, p. 409).

No entanto, a realidade da juventude brasileira ainda não se encontra no ideal proposto pelo argentino, pois "o Rio de Janeiro, não obstante ser a revelação do paraíso, não apresenta a sua juventude harmonizada a seu clima, com a ação material que representa no mundo" (MÁRMOL, 2010, p. 413), uma vez que a imprensa da cidade "não representa uma revolução inteligente: tão pouco uma revolução política; muito menos uma revolução literária" (MÁRMOL, 2010, p. 413).

A ausência dessa revolução transforma o ambiente americano em "um deserto, um deserto ainda virgem aos olhos do homem civilizado" (MÁRMOL, 2010, p. 414), pois "temos uma sociedade nossa, original e estranha pelos dois elementos que a constituem: a civilização e a barbárie; não há termo médio, a Europa do século XIX e a América do século XV, é o que compõe a sociedade americana" (MÁRMOL, 2010, p. 414). A aparência da cultura, pois "tudo é europeu desde o traje e a maneira até as concepções mais altas da vida social" (MÁRMOL, 2010, p. 414), dá a ideia de ambiente atrasado, de colônia. A luta, portanto, começa pela emancipação da própria cultura: "tudo o que hoje temos em política, em instituições, em filosofia, tudo é um cabedal a juros que nos tem emprestado a Europa: - nada temos nosso; - tê-lo-emos alguma vez? Quem sabe!" (MÁRMOL, 2010, p. 415).

Um dos interesses dos ensaios que compõem esse conjunto da Juventude Progressista é discutir a ausência de produções literárias locais. Mármol examina e constata: "tudo entre nós outros são romances e novelas andando, e não há dez romances escritos" (MÁRMOL, 2010, p. 424). Como já deixou claro, não há como construir-se autonomamente sem literatura, sem movimento literário, a arma da juventude, afinal, "faltando a produção, falta a crítica em literatura" (p. 425). Sinaliza, no entanto, que dois nomes da escrita literária estariam fazendo o seu papel: Gonçalves de Magalhães, "o primeiro que importou no Brasil a entoação e a forma da nova lira europeia" (MÁRMOL, 2010, p. 426), e Araújo Porto-Alegre, afirmando que "o povo mais tarde ou mais cedo fará justiça ao primeiro que tem levantado o véu a fonte da poesia nacional, e bebido nela suas belíssimas inspirações" (MÁRMOL, 2010, p. 426).

À exceção desses dois autores, Mármol é enfático:

a juventude progressista do Rio de
Janeiro não representa um movimento
revolucionário, nem em política, nem
em literatura; que a causa não está na
debilidade inteligente, nem nos ele-
mentos que têm sujeitos à sua escolha;
vamos pois a descobrir as causas da
inação, determinando no fim de nosso
discurso os caracteres que é chamada
a desempenhar no grande drama dos
destinos brasileiros (MÁRMOL, 2010,
p. 426-427).

Só poderá existir movimento social quando existir movimento literário; só poderá existir movimento literário quando a literatura produzida no Brasil não for mais uma reprodução dos modelos europeus.

Para Mármol, "as ideias não têm pátria" (MÁRMOL, 2010, p. 446), e não há problema que a literatura local tenha a influência das produções europeias. O que não se pode presumir que a sequência reprodutiva dos modelos europeus seja a única maneira encontrada pelos escritores para fazer a literatura. No entanto, a crítica de seus ensaios deve-se, sobretudo, à tomada de posição que a juventude deve contratar:

temos já completado o pensamento deste artigo; temos procurado a juventude progressista no movimento político e literário; temos determinado as causas que a contêm nesse movimento, e temos por último bosquejado os principios fundamentais com que podem derribar seus obstáculos, dando impulso à revolução moral que acabará por fixar os destinos dessa juventude. tanto no Brasil como na América; deixamos agora em nosso coração a consoladora esperança nos esforços dessa juventude, e deixamos nossa fronte. tão abatida pelo infortúnio da pátria. alegrar-se no florido sonho do porvir americano (MÁRMOL, 2010, p. 446). 
Mármol volta à Argentina em abril de 1846 , confrontando a realidade de seu país e a vivida nas terras brasileiras. O incentivo à cultura e à letra, propiciado pelo imperador Pedro II, possibilitou um espaço que naturaliza a intelectualidade, em que não há lugar sem cerceamento da liberdade de expressão e de imprensa, com autonomia e liberdade de escrita. A realidade brasileira destaca-se e evidencia as significativas diferenças entre o país que o acolheu e a terra que 0 expulsou. A ditadura de Rosas mantém-se atuante até o ano de 1852, mas não aquieta o câmbio entre argentinos e brasileiros, enriquecendo a troca e buscando a autonomia do projeto América.

\section{Considerações finais}

Os ideais de José Mármol apresentam-se claramente definidos. Com a sua experiência de exilio, ojovem literato acredita que somente por meio de uma tomada de posição obtém-se a liberdade política. Dessa forma, advoga que aJjuventude Progressista do Rio de Janeiro comporte-se da mesma maneira: é necessário e fundamental que o corte e as amarras que confrontam a literatura local com o periodo colonial devam ser vencidos e resolvidos para que a verdadeira literatura brasileira - e americana - possa surgir.

Ocorre que os cenários argentino e brasileiro são antagônicos. Enquanto o Brasil goza de um incentivo e de uma estrutura financeira que valoriza e desperta o interesse pela arte e pela literatura, para citar alguns exemplos, a Argentina só podia ter a literatura como um elemento que transgredisse a realidade social censurada de uma ditadura. Nessas perspectivas diferentes, a escrita literária visa, da mesma maneira, a interesses distintos. A literatura, no ambiente ditatorial, serve para resistir; a produzida em solo fértil, direcionase ao projeto de emancipação da imagem do país enquanto nação. Independentemente da intencionalidade, a literatura, seja no Brasil ou na Argentina, deve promover a emancipação cultural de um povo.

É por meio de suas impressões etnográficas que José Mármol estabelece a relação entre natureza e cultura, e contribui, com os seus escritos, ao que Leff define como uma história ambiental. Os escritos ensaísticos de um periódico sinalizam as impressões e as intenções do debate social do Rio de Janeiro daquele período, e confrontam, por exemplo, a história oficial do Brasil nacionalista com a oposição crítica daqueles que não concordavam com tal projeto, pois ele não atingia a plena autonomia e a independência política para o alcance de uma identidade própria e efetivamente emancipada.

O Gênio americano, registro de um projeto de unificação da América, constata o interesse e os desejos dos intelectuais da época em contrapor a influência europeia à construção de um projeto identitário próprio. José Mármol é só um exemplo da escrita plural do ambiente latino-americano, que contou com literatos que pensaram a América com um espírito de luta e de revolta, de independência política, literária e cultural. Sem dúvida, escritos como os de José Mármol contribuem para o projeto de narrativa histórica ambiental de Enrique Leff, porque relatam, além da história contraposta, a história daqueles que eram excluidos - os exilados.

\section{Referências}

LEFF, Enrique. Construindo a história ambiental da América Latina. Esboços: Histórias em Contextos Globais, Florianópolis, v. 12, n. 13, p. 11-29, nov. 2007. ISSN 2175-7976. Disponivel em: https://periodicos. ufsc.br/index.php/esbocos/article/view/383. Acesso em: 10 abr. 2019. doi: https://doi.org/10.5007/ 2175-7976.2019v26n41p42

MÁRMOL, José. Juventude progressista do Rio de Janeiro. Ostensor Brasileiro: Jornal Pictórico e pictorial, Rio de Janeiro, 1845-1846. Fundação Biblioteca Nacional, 2010. Disponivel em: http://memoria.bn.br/ DocReader/DocReader.aspx? $\mathrm{bib}=700100 \times$ \&PagFis $=1$. Acesso em: 20 maio 2015. https://doi.org/10.21115/ jbes.v8.n1.p58-60

MOREIRA, Maria Eunice. Literatos argentinos e brasileiros no império de Pedro II: algumas anotações. Historiae, Rio Grande, v. 6, n. 1, p. 228-244, 2015. ISSN 1519-8502. Disponivel em: https://periodicos.furg.br/ hist/article/view/5415. Acesso em: 10 abr. 2019.

RAMA, Ángel. La ciudad letrada. Montevidéu: Arca, 1998 [1984]. 


\section{Amanda da Silva Oliveira}

Doutora em Teoria da Literatura pela Pontificia Universidade Católica do Rio Grande do Sul (PUCRS); Professora Adjunta da Universidade Federal de Santa Maria (UFSM); Santa Maria, Rio Grande do Sul, Brasil.

\section{Maria Eunice Moreira}

Doutora em Letras (Teoria da Literatura) pela Pontificia Universidade Católica do Rio Grande do Sul (PUCRS); Professora Titular da Pontifícia Universidade Católica do Rio Grande do Sul (PUCRS); Porto Alegre, Brasil.

\section{Endereço para correspondência:}

Amanda da Silva Oliveira

Prédio 40A Cidade Universitária, Av. Roraima, 1000 - Sala 2307. Camobi, Rio Grande do Sul. 97105-900. Brasil.

\section{Maria Eunice Moreira}

Endereço para correspondência. Avenida Ipiranga, 6681. Prédio 8 - $4^{\circ}$ andar, sala 403. Porto Alegre/RS. 90619-900. Brasil. 